\title{
Budyko Yaklaşımına Dayanan Bir Su Bütçesi Modeli ve Parçacık Sürü Optimizasyonu Algoritması ile Kalibrasyonu
}

\author{
Umut Okkan ${ }^{1, *}$, Umut Kırdemir ${ }^{2}$ \\ ${ }^{1}$ Balıkesir Üniversitesi, Mühendislik Mimarlık Fakültesi, Inşaat Mühendisliği Bölümü, Hidrolik Anabilim Dalı, 10145, Balıkesir. \\ 2'izmir Yüksek Teknoloji Enstitüsü, Inşaat Mühendisliği Anabilim Dalı, İzmir.

\section{Özet}

Sunulan çalışmada, aylık yağış-akış ilişsisini tanımlamak amacıyla Budyko yaklaşımına dayanan bir su bütçesi modeli kullanılmıştır. Önerilen beş parametreli model girdi olarak sadece aylık ortalama yağış ve potansiyel evapotranspirasyon verilerine ihtiyaç duymaktadır. Çalışma sahası Gediz Havzası'ndaki Nif Çayı'nı kapsamaktadır. Model parçacık sürü optimizasyonu algoritması (PSO) ile kalibre edilmiştir. PSO ile kalibre edilen modelin performansını sinamak maksadiyla istatistiksel ölçütler değerlendirilmiştir. Çalışmadan elde edilen bulgular, su bütçesi modelinin aylık akış serilerini modellemede başarllı olduğunu göstermiştir.

\section{Anahtar Sözcükler}

Su Bütçesi Modeli, Budyko Yaklaşımı, Parçacık Sürü Optimizasyonu, Nif Çayı

\section{A Water Balance Model Based on Budyko Framework and Its Calibration through Particle Swarm Optimization Algorithm}

\begin{abstract}
In the study presented, to define monthly rainfall-runoff relation, a water budget model based on Budyko approach was used. Proposed five-parameter model requires only monthly mean precipitation and potential evapotranspiration data as input. The study region covers the Nif Creek located at the Gediz Basin. Model was calibrated with particle swarm optimization (PSO) algorithm. To validate the performance of model calibrated via PSO, statistical measures were assessed. The results derived from the study show that water budget model is successful in modeling of monthly runoff series.
\end{abstract}

$\underline{\text { Keywords }}$

Water Budget Model, Budyko Framework, Particle Swarm Optimization

\section{Giriş}

Akarsu havzalarındaki yağış-akış ilişkisinin belirlenmesi, akım rasatları olmayan havzalarda akım tahmini, eksik akım verilerinin tamamlanması, iklim değişikliğinin akarsu akışlarına olası etkilerinin modellenmesi ve havzanın yeraltı suyu depolamasının incelenmesi gibi önemli hidrolojik konular kapsamında su bütçesi modellerinden yararlanılmaktadır. Bir havzadaki su bütçesi, iklime ve havza karakteristiklerine bağlı olup bu ilişkinin tanımlanması genellikle doğrusal yaklaşımlarla mümkün olmamakta, zamansal-konumsal açıdan karmaşıklık içermektedir. Söz konusu ilişkinin belirlenmesi için bazen fazla sayıda veriye ve parametreye ihtiyaç duyulabilmektedir. Bu durumda kurulan model kalibrasyon (ayarlama) sürecinde iyi sonuç verirken, verifikasyon (doğrulama) aşamasında genelleme yeteneğini kaybedebilmektedir. Ayrıca bu tarz modeller komşu havzalara kolaylıkla adapte edilebilir nitelikte olamayabilmektedir. Bu nedenle uygulamada daha az girdi ile çalıştırılan ve daha az parametre muhteva eden modeller tercih edilmektedir (Makhlouf ve Michel 1994; Fistıkoğlu ve Harmancığlu 2001).

Budyko (1958), su bütçesi ve iklim karakteristikleri arasındaki ilişkinin araştırıldığı bir çalışmasında havzadaki uzun dönem ortalama evapotranspirasyonun yağış ve mevcut enerjiden elde edilebileceğini ifade etmiştir. "Budyko e ğrisi" olarak da bilinen yaklaşımın uzun dönem su bütçesi analizlerinde makul sonuçlar verdiği görülmüş ve yöntem çeşitli teorik çalışmalara zemin oluşturmuştur (Milly 1994; Choudhury 1999; Atkinson vd. 2002; Farmer vd. 2003 ; Zhang vd. 2008).

Sunulan çalışmada, Zhang vd. (2008) tarafından önerilen ve Budyko yaklaşımına dayanan dört parametreli model esas alınmıştır. Zhang vd. (2008) bu modeli dinamik su bütçesi modeli olarak adlandırmıştır. Modelin yeraltı suyu biriktirme sistemi için ilave bir parametre tanımlanarak aylık zaman ölçeğinde hazırlanan beş parametreli model Gediz Havzası'nda yer alan Nif Çayı alt havzasına uygulanmıştır. Modelin parametreleri Parçacık Sürü Optimizasyonu (PSO) 
algoritması yardımıyla kalibre edilmiştir. PSO algoritması kuş ve balık gibi hayvan sürülerinin davranışlarından esinlenilerek Kennedy ve Eberhart (1995) tarafından geliştirilmiştir. Parçacık sürü optimizasyonu birçok mühendislik probleminde kullanılmakla birlikte hidroloji konseptinde de uygulamalarına rastlamak mümkündür (Gill vd. 2006; Chau 2006; Reddy ve Kumar 2007; Chu ve Chang 2009). Algoritmanın yağış-akış modeli kalibrasyonunda uygulaması ise sınırlı sayıdadır (Goswami ve O'Connor 2007; Kuok vd. 2011). Hazırlanan çalışmada, beş parametreli su bütçesi modeli-PSO entegrasyonu araştırmacılara yol gösterecektir. Kullanılan verilere ve ele alınan yönteme ait detaylar aşağıda verilmektedir.

\section{Veriler}

Sunulan çalışmada, su bütçesi modeli Gediz Havzası'nda yer alan yaklaşık $850 \mathrm{~km}^{2}$ yağış alanına sahip Nif Çayı alt havzasına uygulanmıştır (Şekil 1). DSİ tarafından işletilen D05A038 numaralı Hacıhaliller akım gözlem istasyonunda gözlenen doğallaştırılmış akımların 01.10.1976-01.09.2010 dönemine (1976-2010 su yılları) ait verileri kullanılmıştır. Uygulama havzasını temsil eden yağış ve sıcaklık verileri, Meteoroloji Genel Müdürlüğü (MGM) tarafından işletilen Turgutlu, Kemalpaşa, Muradiye ve Manisa istasyonlarında ölçülmektedir. Turgutlu, Kemalpaşa ve Muradiye istasyonlarına ait bazı dönemlerde verilerde eksiklikler olup bu eksik veriler eksiği bulunmayan Manisa istasyonu verileri ile kurulan regresyon ilişkileri ile tamamlanmıştır. İstasyon verilerinin 01.10.1975-01.09.2010 ortak dönemine ait yıllık ortalamaları Tablo 1'de verilmiştir. Çalışmada bölge için Thiessen poligonu oluşturularak alansal ortalama yağışlar kullanılmıştır. Elde edilen poligonlar Şekil 1'de gösterilmiştir. Tahmini potansiyel evapotranspirasyon (EPOT) değerleri ise Thornthwaite ampirik denkleminden hesaplanmıştır (Denklem 1, 2, 3 ve 4).

$$
\begin{aligned}
& I_{i}=\left(T_{i} / 5\right)^{1.514} \\
& J=\sum_{i=1}^{12} I_{i} \\
& c=0.000000675 J^{3}-0.0000771 J^{2}+0.01792 J+0.49239 \\
& E P O T=16\left(10 T_{i} / J\right)^{c} . K
\end{aligned}
$$

Burada T aylık ortalama sıcaklı̆g $1\left({ }^{\circ} \mathrm{C}\right), I_{i}$ ilgili yıla ait i.ayın sıcaklık indeksini, $J$ ise o y1la ait sicaklık indeksini, $K$ ise istasyonların bulunduğu boylamlara göre elde edilen düzeltme katsayısını ifade etmektedir.

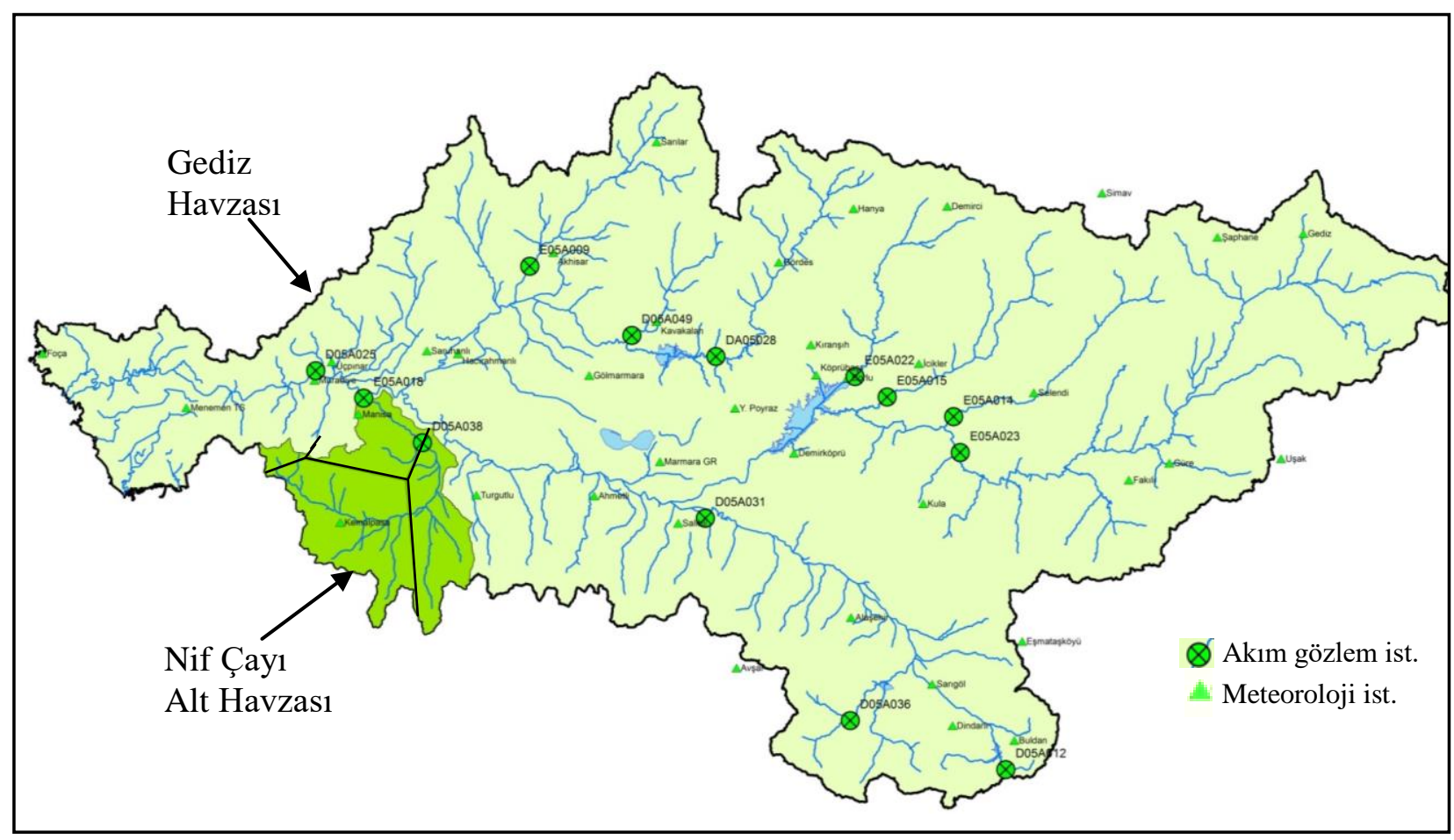

Şekil 1: Nif Çayı alt havzasının Gediz Havzası üzerindeki konumu ve hidro-meteoroloji istasyonları 
Tablo 1: Gözlemlerin 01.10.1975 - 01.09.2010 dönemine ait yıllık ortalama değerleri

\begin{tabular}{|l|c|c|c|c|c|}
\hline \multirow{2}{*}{$\begin{array}{l}\text { İstasyon Adı } \\
\text { (Numarası) }\end{array}$} & \multirow{2}{*}{$\begin{array}{c}\text { İşleten } \\
\text { Kuruluş }\end{array}$} & $\begin{array}{c}\text { Yağış } \\
(\mathbf{m m} / \mathbf{y} \mathbf{l})\end{array}$ & $\begin{array}{c}\text { Sıcaklık } \\
\left({ }^{\mathbf{0}} \mathbf{C} / \mathbf{y l l}\right)\end{array}$ & $\begin{array}{c}\text { EPOT } \\
(\mathbf{m m} / \mathbf{y} \mathbf{l})\end{array}$ & $\begin{array}{c}\text { Akış } \\
(\mathbf{m m} / \mathbf{y} \mathbf{l})\end{array}$ \\
\hline Manisa (17186) & MGM & 698.9 & 17.05 & 933.2 & - \\
\hline Muradiye (5440) & MGM & 581.8 & - & - & - \\
\hline Turgutlu (5615) & MGM & 523.4 & 16.72 & 904.3 & - \\
\hline Kemalpaşa (5785) & MGM & 923.3 & 16.33 & 875.7 & - \\
\hline $\begin{array}{l}\text { Nif Çay1-Hacıhaliller } \\
\text { (D05A038) }\end{array}$ & DSI & - & - & - & 123.8 \\
\hline
\end{tabular}

\section{Budyko Yaklaşımına Dayanan Su Bütçesi Modeli}

Budyko (1958), yağıştan tahmin edilen su içeriğine ve evapotranspirasyona bağlı yıllık zaman ölçekli bir su bütçesi eşitliği önermiştir (Denklem 5).

$$
\frac{E T}{P}=1+\frac{E_{0}}{P}-\left[1+\left(\frac{E_{0}}{P}\right)^{\frac{1}{1-\alpha}}\right]^{1-\alpha}
$$

Burada $E_{0}$ potansiyel evapotranspirasyonu (EPOT), ET gerçek evapotranspirasyonu, $P$ yağışı, $\alpha$ tanım aralığı $(0,1)$ olan model parametresini temsil etmektedir. Buradaki $E_{0} / P$ ifadesi ise kuraklık indeksi olarak bilinmektedir. Denklem 5'e göre sabit bir $E_{0} / P$ oranı için $\alpha$ arttıkça evapotranspirasyon etkinliği de artar. Denklem 5, $i$. zaman (yıl veya ay) için Denklem 6'daki şekliyle yazılarak Fu eğrisi olarak tanımlanmaktadır (Fu 1981).

$$
\left(\frac{E T}{P}\right)_{i}=F\left(\left(\frac{E_{0}}{P}\right)_{i} ; \alpha\right)
$$

Denklem 5 düzenlenerek Denklem 7'deki ifade yazılabilir. Kararlı hal kabulüne göre biriktirme terimleri ihmal edilerek havzadaki yıllık akım için $Q=P$-ET kabul edilirse, Denklem 7'deki ifadede her iki tarafın (1- $\alpha)$ ile üssü alınıp $(P$-ET) fark ifadesi yerine $Q$ yazıldığında yıllık akım $(Q)$ eşitliği elde edilmektedir (Denklem 8).

$$
\begin{aligned}
& P^{\frac{1}{1-\alpha}}+E_{0}^{\frac{1}{1-\alpha}}=\left(P+E_{0}-E T\right)^{\frac{1}{1-\alpha}} \\
& Q_{i}=\left[P_{i}^{\frac{1}{1-\alpha}}+E_{0, i} \frac{1}{1-\alpha}\right]^{1-\alpha}-E_{0, i}
\end{aligned}
$$

Yıllık zaman ölçeğinden aylık zaman ölçeğine geçildiğinde yağıştaki, potansiyel evapotranspirasyondaki ve depolamadaki değişkenliklerin dikkate alınması gerekmektedir. Zhang vd. (2008) bu durumu kanıtlamak için Denklem 8'de verilen yıllık su bütçesi eşitliğini aylık verilere uygulamışlardır. Elde ettikleri sonuçlara göre, aylık verilere uygulanan yıllık su bütçesi modelinin aylık akımları temsil etmedeki başarısı zayıf kalmıştır. Tahmini akımların yağışlara oldukça duyarlı olduğu tespit edilmiş; model tahminleri gözlenen akımlara kıyasla oldukça büyük çıkmıştır. $\mathrm{Bu}$ sonuçlar, ilave süreçlerin de model işleyişine yansıtılmasını gerekli kılmıştır. Bu maksatla, Zhang vd. (2008) Budyko eğrisini esas alarak dinamik su bütçesi modeli olarak adlandırdıkları modeli ortaya koymuşlardır.

$\mathrm{Bu}$ modelde havza, zemin nemi ve yeraltı suyu depolaması olmak üzere iki aşamada kavramsallaştırılmıştır. $t$. zamanda havzaya düşen yağış $(P(t))$, dolaysız akışa $Q_{d}(t)$ ve havza tarafından diğer su bütçesi elemanları için tutulan su miktarına $(X(t))$ paylaştırılmaktadır (Denklem 9, Şekil 2a).

$$
P(t)=Q_{d}(t)+X(t)
$$




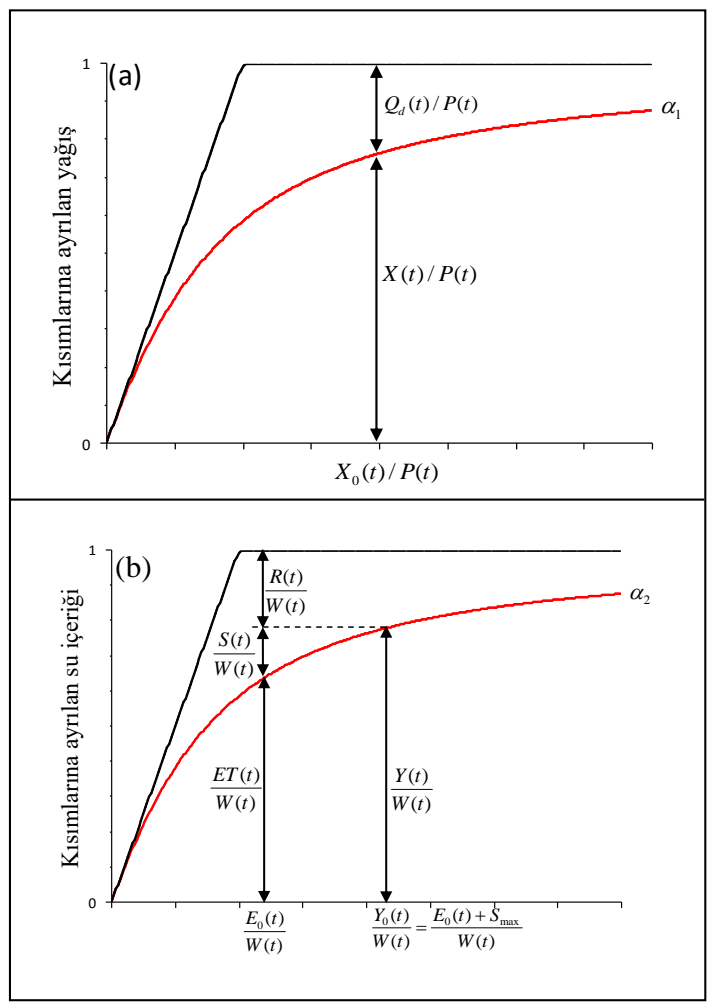

Şekil 2: Yağışın bileşenlerine ayrılması (a), mevcut suyun kısımlarına ayrılması (b)

Burada, gerçek evapotranspirasyon $E T(t)$, zemin nemindeki değişim $S(t)$-S(t-1) ve yeraltı suyu biriktirme sistemine boşalan su $R(t)$ bileşenlerinin toplamı $X(t)$ 'yi temsil etmektedir. Zemin nemi depolaması $S(t)$ maksimum doygunluğa eriştiğinde $\left(S(t)=S_{\max }\right) X(t)$ için beklenen üst limit $X_{O}(t)$ aşağıdaki şekliyle tanımlanmaktadır (Denklem 10).

$$
X_{0}(t)=S_{\max }-S(t-1)+E_{0}(t)
$$

Budyko (1958)'de savunulan görüşe benzer olarak $X_{o}(t) / P(t) \rightarrow \infty$ için (aşırı kurak) $X(t) / P(t) \rightarrow 1$ çıkarımını yapmak mümkündür. $X_{O}(t) / P(t) \rightarrow 0$ için (aşırı sulak) ise $X(t) \rightarrow X_{O}(t)$ limit değerine yakınsar. Fu fonksiyonu $X_{O}(t) / P(t)$ oranına uyarlanarak $X(t)$ hesaplanabilmektedir (Denklem 11, Şekil 2a).

$$
X(t)=P(t) \cdot F\left(\frac{X_{0}(t)}{P(t)} ; \alpha_{1}\right)
$$

Burada $\alpha_{1}$ dolaysız akış haricindeki su bütçesi elemanları için tutulan su miktarını kontrol eden model parametresidir. $X(t)$ hesaplandıktan sonra akımın dolaysız bileşeni Denklem 9'dan elde edilmektedir.

Bir önceki aydan kalan zemin nemi ile $X(t)$ toplamı $t$. ayda havzada mevcut bulunan su miktarını $(W(t))$ temsil etmektedir (Denklem 12).

$$
W(t)=S(t-1)+X(t)
$$

Bu mevcut suyun bir kısmı evapotranspirasyona ayrılacak, bir kısmı zemin nemi depolamasında kalacak, geri kalan kısmı ise yeraltı suyu depolama sistemini besleyecektir (Denklem 13, Şekil 2b).

$$
W(t)=E T(t)+S(t)+R(t)
$$

t. ayda gerçekleşen evapotranspirasyon ve depolanan zemin nemi toplamı $Y(t)$ ile gösterilirse $(Y(t)=E T(t)+S(t)), Y(t)$ için beklenen üst limit değeri $Y_{0}(t)$ ise $S(t)=S_{\max }$ ve $E T(t)=E_{0}(t)$ için aşağıdaki gibi tanımlanmaktadır.

$$
Y_{0}(t)=S_{\max }+E_{0}(t)
$$


Budyko (1958)'e benzer biçimde, $Y_{0}(t) / W(t) \rightarrow \infty$ için (aşırı kurak) $Y(t) / W(t) \rightarrow 1$, aksi durum (aşırı sulak) için $Y_{0}(t) / W(t) \rightarrow 0$ için $Y(t) \rightarrow Y_{O}(t)$ çıkarımı yapılmaktadır. $Y(t)$ Fu eğrisi ile $\alpha_{2}$ evapotranspirasyon etkinlik parametresine bağlı olarak tahmin edilmektedir (Denklem 15).

$$
Y(t)=W(t) \cdot F\left(Y_{0}(t) ; \alpha_{2}\right)
$$

Y(t) hesaplandığında yeraltı suyu depolamasına boşalan su Denklem 16 ile hesaplanmaktadır.

$$
R(t)=W(t)-Y(t)
$$

$E T(t)$ bileşeninin beklenen limit değeri ise potansiyel evapotranspirasyon $E_{0}(t)$ 'dir. Benzer şekilde, $E T(t) \mathrm{Fu}$ eğrisinden $\alpha_{2}$ parametresine bağlı hesaplanabilmektedir (Şekil 2b, Denklem 17).

$$
E T(t)=W(t) \cdot F\left(\frac{E_{0}(t)}{W(t)}, \alpha_{2}\right)
$$

Denklem 15 ve Denklem 17 aynı $\alpha_{2}$ parametresini kullanmaktadır. $\alpha_{2}$ arttıkça $E T(t)$ ve $Y(t)$ artmakta ve buna bağlı olarak $R(t)$ azalmaktadır. $Y(t)$ ve $E T(t)$ hesaplandıktan sonra $t$. aya ait zemin nemi depolaması elde edilebilmektedir $(0 \leq$ $\left.S(t) \leq S_{\max }\right)$.

$$
S(t)=Y(t)-E T(t)
$$

Son aşamada, yeraltı suyu depolaması lineer hazne kabulü ile ele alınmakta ve taban akışı bir önceki aydan kalan yeraltı suyu depolama miktarına bağlı olarak hesaplanmaktadır (Denklem 19).

$$
Q_{b}(t)=\beta \cdot G(t-1)
$$

Burada $Q_{b}(t)$ taban akışını, $\beta$ doğrusal yeraltı suyu haznesi parametresidir. $G(t-1)$ bir önceki ayın aktif yeraltı suyu depolamasıdır. Yeraltı biriktirme sisteminin $t$ ayındaki aktif kapasitesi $G(t)$ ise Denklem 20 ile hesaplanmaktadır.

$$
G(t)=[G(t-1)+R(t)] \cdot \xi-Q_{b}(t)
$$

Burada $\xi$, yeraltı biriktirme sistemi parametresidir. $\mathrm{Bu}$ parametre modelin 4 parametreli versiyonunda bulunmamaktadır. Su bütçesi elemanları tanımlandıktan sonra modellenen toplam akış Denklem 21'den hesaplanmaktadir.

$$
Q_{m}(t)=Q_{d}(t)+Q_{b}(t)
$$

Modelin $S_{\max }, \alpha_{1}, \alpha_{2}, \beta$ ve $\xi$ parametreleri parçacık sürü optimizasyonu (PSO) algoritması ile kalibre edilmiştir. PSO yöntemine ait detaylar ise aşağıda verilmiştir.

\section{Parçacık Sürü Optimizasyonu (PSO) Algoritması}

PSO algoritması kuş ve balık gibi hayvan sürülerinin çevrelerine adapte olma, yiyecek arama ve avcılardan kaçma gibi sosyal davranışlarından esinlenerek geliştirilmiş bir yöntemdir (Kennedy ve Eberhart 1995). PSO, parçacık denen bireyler arasındaki etkileşimden yararlanmakta ve bireyleri arama uzayındaki en iyi bölgeye doğru yönlendirmektedir. PSO algoritmasında rastgele çözümler taşıyan bir parçacık sürüsü ile işlemlere başlanılmakta ve önceden belirlenen bir uygunluk fonksiyonu $F(x)$ için iteratif olarak en uygun çözüm bulunmaya çalışılmaktadır. PSO, arama uzayında optimum çözümü bulmaya çalışırken, uygunluk fonksiyonunun olası çözümlerini içeren parçacıklar (popülasyon) kullanması bakımından Genetik Algoritma (GA) ile benzerlik göstermektedir.

Sürü içerisindeki her bir kuş (parçacık) bilinmeyen parametre adedi kadar sonuç yani pozisyon $(p)$ üretmektedir. Kuşlar her bir iterasyonda pozisyonlarını hafızasına almakta ve mevcut parçacıklar içinde en iyi uygunluk değerini veren pozisyon belirlenmektedir. Bu pozisyon yerel en iyi (pbest) olarak adlandırılmaktadır. PSO'da, parçacık hızları ve konumları güncellenirken pbest'in yanı sıra o ana kadar tüm parçacıklardan elde edilen en iyi uygunluk değerini veren konuma yani global en iyi sonuca (gbest) da bakılmaktadır. Bu arama işlemi maksimum iterasyon adedine ulaşıldığında sonlandirılmaktadır. 
$d=1,2, \ldots D$ olmak üzere $D$ adet parametre tanımlanan bir arama uzayında hareket eden $N$ adet parçacık için $N x D$ boyutlu konum ve hız matrisi elde edilmektedir. $i=1,2, \ldots N$ olmak üzere $i$. parçacığın $k$. iterasyon sonunda güncellenmiş hızı ve güncellenmiş konumu sırasıyla Denklem 22 ve Denklem 23 ile belirlenmektedir.

$$
\begin{aligned}
& v_{i, d}{ }^{k+1}=v_{i, d}{ }^{k}+c_{1} r_{1}{ }^{k}\left(\text { pbest }_{i, d}{ }^{k}-p_{i, d}{ }^{k}\right)+c_{2} r_{2}{ }^{k}\left(\text { gbest }_{d}{ }^{k}-p_{i, d}{ }^{k}\right), d=1,2, . ., D \\
& {p_{i, d}{ }^{k+1}}^{k}={p_{i, d}}^{k}+{v_{i, d}}^{k+1}
\end{aligned}
$$

Denklemlerde, $v$ hızı, $p$ konumu göstermektedir. $c_{1}$ katsayısı parçacığın kendi tecrübeleri ile hareketini kontrol ederken, $c_{2}$ katsayısı ile komşu parçacıkların tecrübeleri de hesaba katılır. Buradaki $r_{l}$ ve $r_{2}$ ise $[0,1]$ arasında değişen rastgele atanmış pozitif reel sayılardır. Algoritmada $c_{1}$ ve $c_{2}$ katsayıları bu sayılarla çarpılarak her bir adımda stokastik ivmelenme sabitleri haline dönüşmektedirler. PSO algoritmasının akış şeması Şekil 3’te özetlenmiştir.

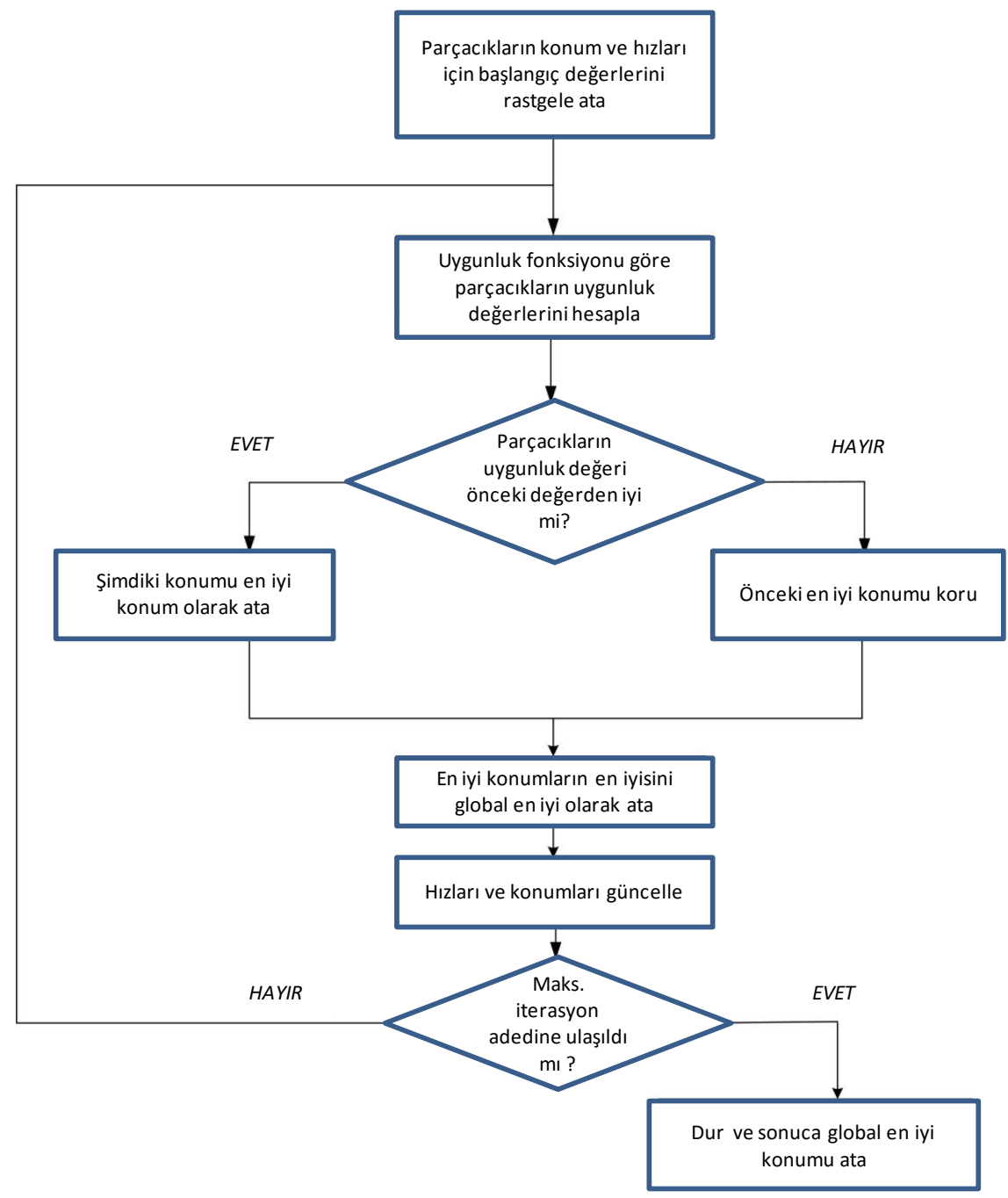

Şekil 3: PSO algoritmasının akış şeması

\section{Uygulama}

Detayları yukarıda verilen PSO ile kalibre edilen su bütçesi modeli, MS Excel (VBA) ortamında kodlanarak geliştirilmiştir. Kurulan model, zemin nemi ve yeraltı suyu başlangıç depolama değerleri olan $S(t=0)$ ve $G(t=0)$ değerlerini okuyarak işleme başlamakta ve her bir ay için su bütçesi bileşenlerini hesaplamaktadır. Başlangıç koşulları, model sonuçları ilk aylarda ölçülmüş akımlara yakın olacak şekilde belirlenmektedir. Çalışmada, Nif Çayı alt havzasının 35 yıllık gözleminin ilk 18 yılı (1976-1993) kalibrasyon aşamasında, diğer 17 yıllık kısmı (1994-2010) verifikasyon aşamasında kullanılmıştır. 
PSO ile parametre kalibrasyonuna geçmeden önce algoritmaya ait başlangıç koşulları oluşturulmuştur. Hata kareler ortalaması (HKO) uygunluk fonksiyonu olarak seçilmiş ve HKO değerinin minimizasyonu esas alınmıştır. Su bütçesi modelinde kalibre edilecek parametre sayısı beş olduğu için $D=5$ alınmıştır. Parçacık sayısı (N) ve c sabitleri problemden probleme değişkenlik göstermekle birlikte bu çalışma için farklı denemeler yapılmıştır. Gözlemlere göre parçacık sayısının fazla olması $(\mathrm{N}>10-20)$ durumunda işlem süresi uzamakta, az olması durumunda ise yeterli kalibrasyon sağlanamamaktadır. c1 ve c2 katsayıları ise rassal değerler ile çarpıldığından kalibrasyon üzerindeki etkisi parçacık sayısının etkisinden daha azdır. Bu çalışmada farklı denemeler neticesinde $\mathrm{N}=10, \mathrm{c}_{1}=\mathrm{c}_{2}=2$ kabulleri oldukça makul kalibrasyon sonuçları vermiş ve çalışmada sadece bu kabullere ait bulgular sunulmuştur. Başlangıçta $S_{\text {max }}, \alpha_{1}, \alpha_{2}$, $\beta$ ve $\xi$ parametrelerinin konumları için rastgele değerler atanmıştır. Başlangıçtaki hız değerleri ise 0 kabul edilmiştir. Su bütçesi modelindeki parametrelerin de sınırları olduğundan konum değerleri belli kısıtlar dikkate alınarak güncellenmiştir. Örneğin $S_{\max }$ değeri fiziksel olarak negatif değer alamaz. Benzer olarak $\beta>1$ durumu gözlenemez. Bu nedenle $S_{\max }$ için tanım aralığı $[300,900]$ seçilmiş; diğer parametreler için ise tanım aralığı $[0.1,0.9]$ alınmıştır. Algoritmada maksimum iterasyon adedi 100 alınmıştır. İlk iterasyon, 2. iterasyon, en iyi sonucun elde edildiği 21. iterasyon ve son iterasyon için yapılan hesaplamalar Tablo 2'de verilmiştir. Tablo 2'de içi gri dolgulu değerler pbest değerlerini, altı çizili değerler ise gbest değerlerini göstermektedir. Buna göre $S_{\max }=851.294 \mathrm{~mm}, \alpha_{1}=0.528, \alpha_{2}=0.478$, $\beta=0.611$ ve $\xi=0.439$ olarak tahmin edilmiştir.

Parametre kalibrasyonu tamamlandıktan sonra su bütçesi modelinin kalibrasyon ve verifikasyon dönemlerindeki performansları incelenmiştir. Modelden elde edilen tahmini akışların gidiş çizgisi Şekil 4'te verilmiştir. Şekil 4'e göre sonuçlar uyumlu gözükmektedir. Ancak bu aşamada istatistiksel kriterlerin de incelenmesi faydalı olacaktır. Bu kapsamda, $\mathrm{R}^{2}$ (determinasyon katsayısı), Adj. $\mathrm{R}^{2}$ (düzeltilmiş determinasyon katsayısı) ve hata kareler ortalaması gibi kriterler sıklıkla kullanılmaktadır. Moriassi vd. (2007), Nash-Sutcliffe (NS) katsayıs1, hata kareler ortalamasının karekökünün (RMSE) ölçülmüş akımın standart sapmasına oranı (RSR) ve yanlılık oranı (PBIAS) gibi başarı ölçütlerinin kullanımını önermektedir. Moriassi vd. (2007)'e göre $0.75<\mathrm{NS} \leq 1,0 \leq \mathrm{RSR} \leq 0.50$ ve PBIAS $< \pm 10$ sağlanıyorsa model performansı çok iyidir. Söz konusu kriterlere ilişkin açıklamalar Okkan ve Inan (2014) tarafından verilmiştir. Bahsi geçen performans kriterlerini kapsayan hesaplar Tablo 3’te sunulmaktadır.

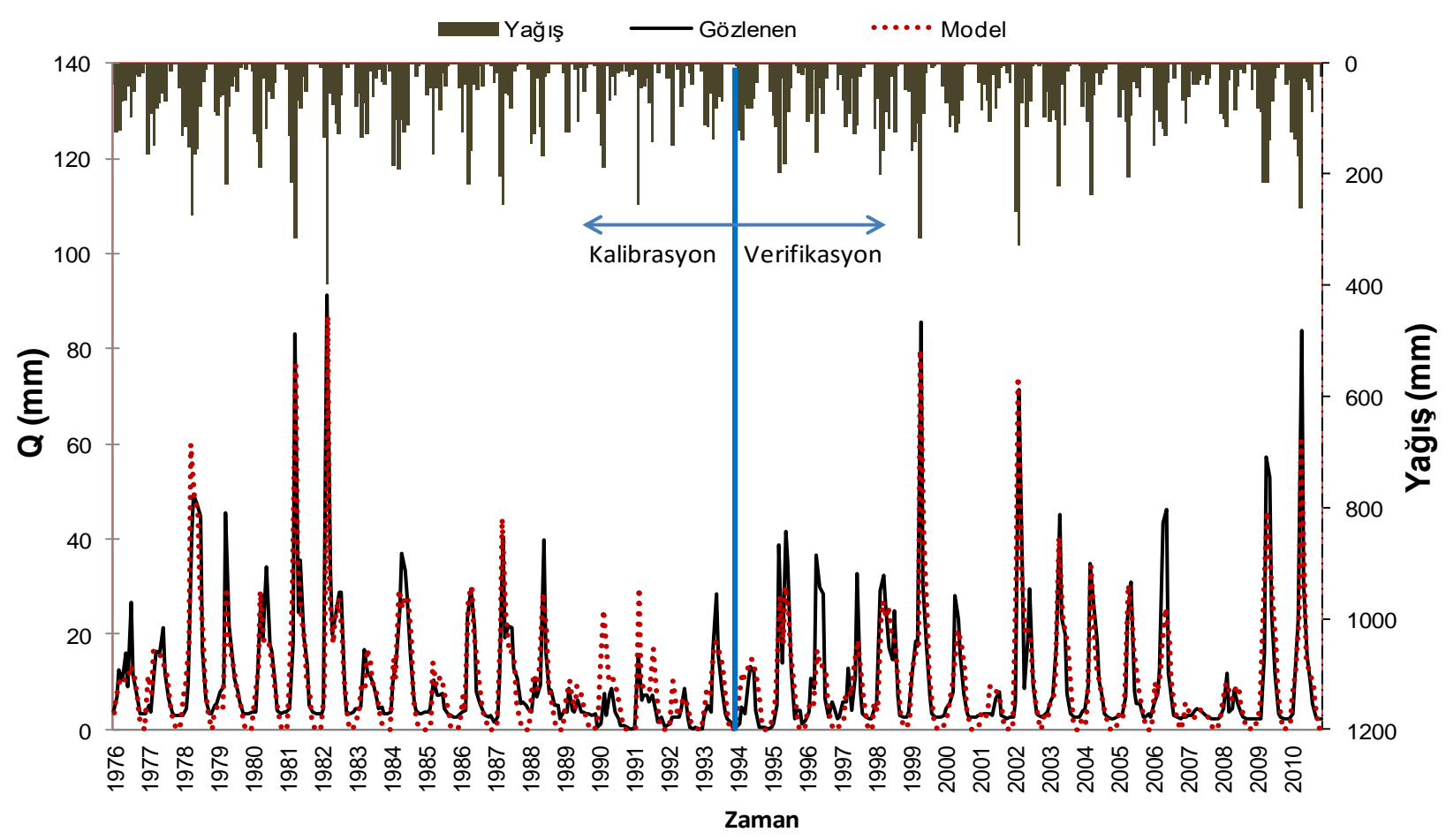

Şekil 4: Modelden elde edilen tahmini akışların gidiş çizgisi 


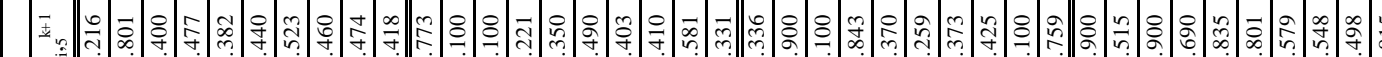

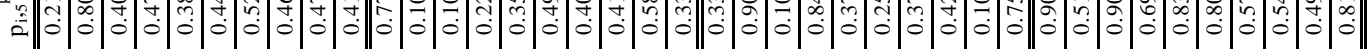

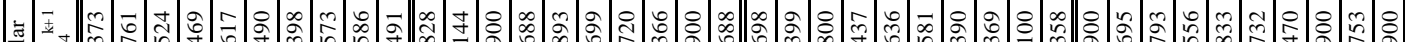

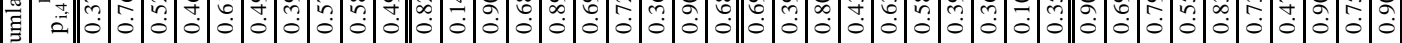

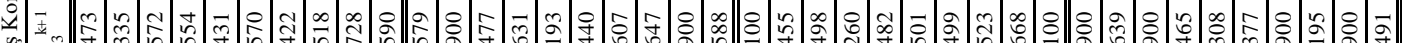

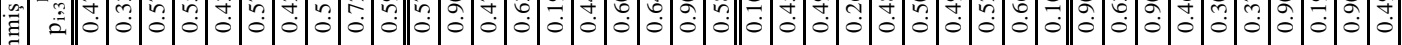

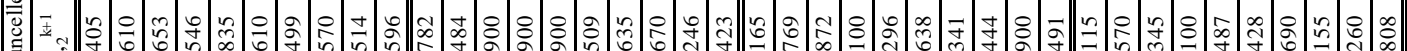

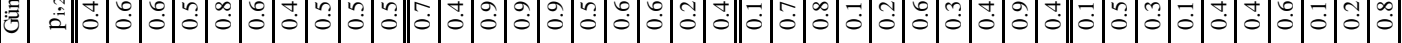

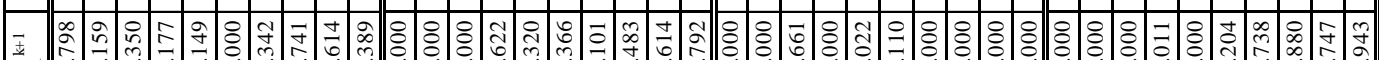

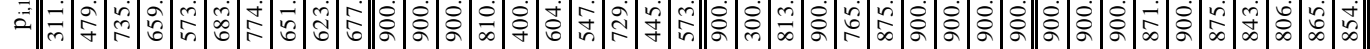

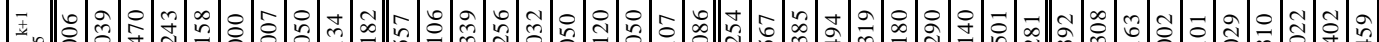

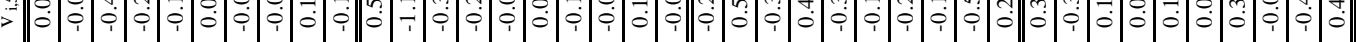
年

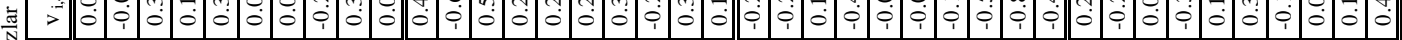

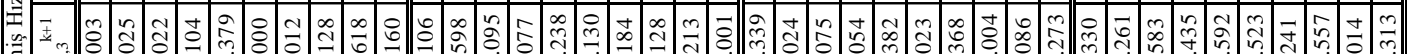

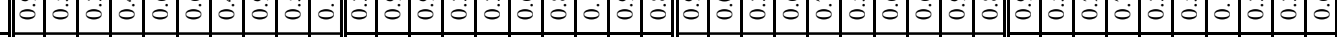

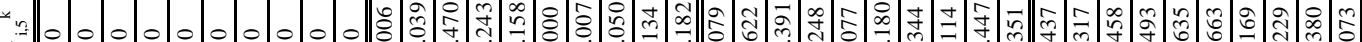

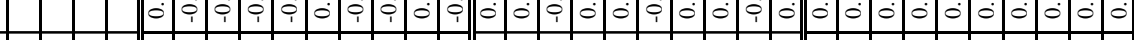

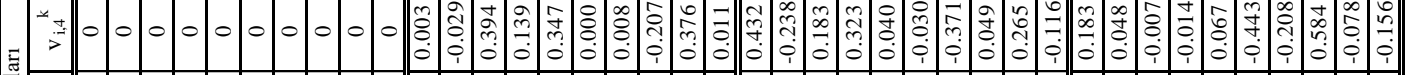

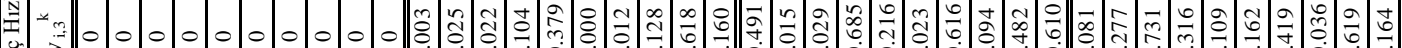
要

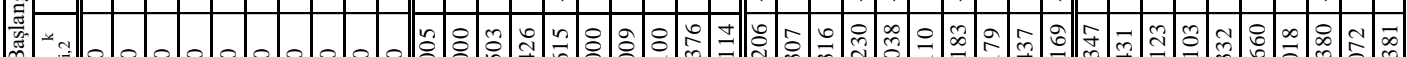
(1)

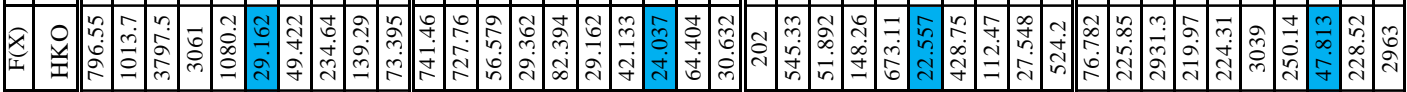

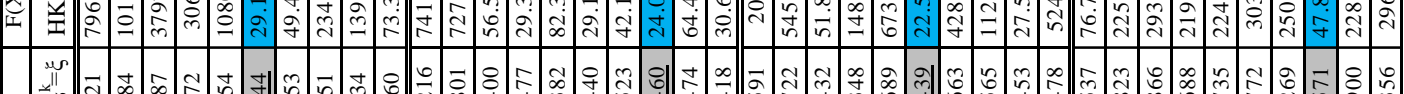

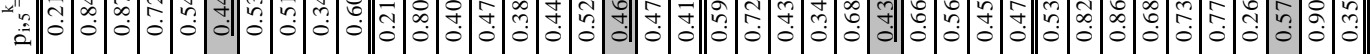

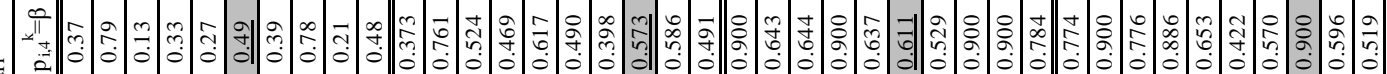
:

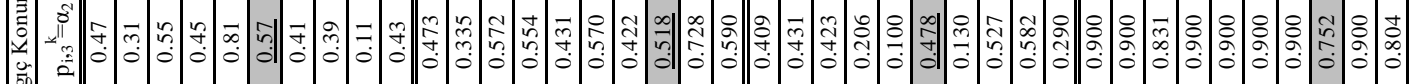

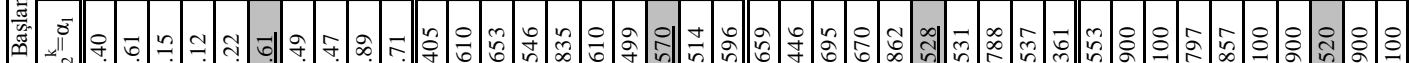
A

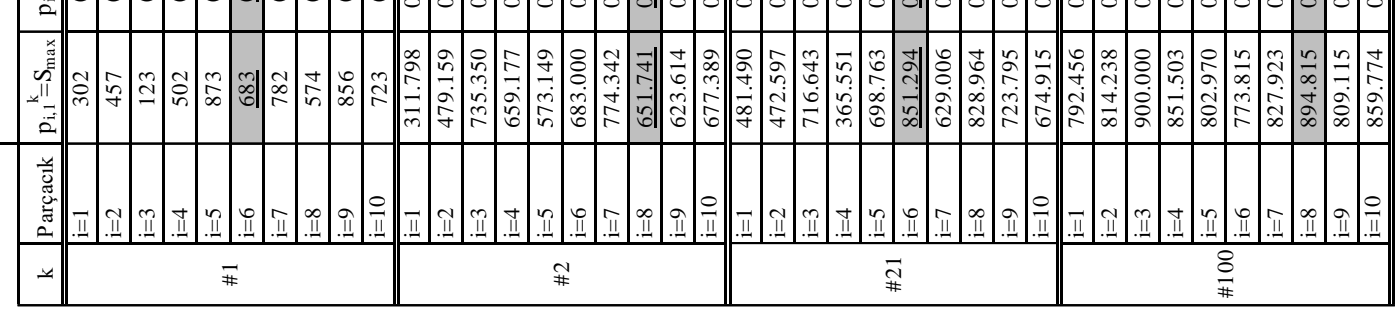


Tablo 3: Kullanılan su bütçesi modelinin performansı

\begin{tabular}{lcccccc}
\cline { 2 - 6 } & $\begin{array}{c}\text { RMSE } \\
(\mathrm{mm})\end{array}$ & $\begin{array}{c}\mathrm{R}^{2} \\
(-)\end{array}$ & $\begin{array}{c}\text { Adj. } \mathrm{R}^{2} \\
(-)\end{array}$ & $\begin{array}{c}\text { NS } \\
(-)\end{array}$ & $\begin{array}{c}\text { RSR } \\
(-)\end{array}$ & $\begin{array}{c}\text { PBIAS } \\
(\%)\end{array}$ \\
\hline Kalibrasyon & 4.74 & 0.8592 & 0.8579 & 0.8570 & 0.3781 & 0.9388 \\
Verifikasyon & 5.81 & 0.8292 & 0.8275 & 0.8267 & 0.4163 & 4.8585 \\
\hline
\end{tabular}

\section{Sonuçlar}

Çalışmada uygulanan hidrolojik modelin Nif Çayı alt havzasındaki istatistiksel performansları dikkate alındığında, aylık yağış-akış ilişkisini başarı ile temsil ettiği düşünülmektedir. Model eksik akım gözlemi bulunan akım gözlem istasyonlarında akışların tamamlanması, akarsu rejiminin yağış ve sıcaklıklara karşı duyarlılıklarının irdelenmesi, iklim değişikliğinin akımlara olası etkilerinin tartışılması gibi amaçlar için kullanılabilir. Örneğin söz konusu modelin iklim modelleri ile entegrasyonu 114Y716 numaralı TUBİTAK projesi kapsamında gerçekleştirilmekte olup proje çıtılarına http://gediz-iklim.com/ adresinden erişilebilir.

Parametrik yağış-akış modelleri bir havzanın evapotranspirasyon, sızma, yüzeyaltı depolaması-yüzeyaltı akışı ile yeraltı depolaması-yeraltı akışı gibi hidrolojik bileşenlerini kavramsallaştırarak, yağış girdisini havza çıkışındaki akışa dönüştürmektedir. Bu aşamada kullanılan parametreler, havzaların ölçülebilen fiziksel parametreleri (havza alanı, eğimi, vb.) olabildiği gibi kavramsallaştırma ile ortaya atılan parametreler de (Maksimum zemin nemi depolaması, yeraltı biriktirme sistemi parametresi vb.) olabilmektedir (Xu ve Singh 1998; Fistıkoğlu ve Okkan 2010). Bu çalışmada bahsi geçen parametreler de kavramsal parametrelerdir.

Çalışmada sunulan su bütçesi modeli $S_{\max }, \alpha_{1}$ ve $\alpha_{2}$ gibi hassas kavramsal parametreler içermekte ve kalibrasyonunun iyi yapılması önerilmektedir (Zhang vd. 2008). Çalışmada PSO algoritması Newton'un teğetler yöntemi ve Genetik Algoritma gibi yöntemlerle de kıyaslanmıştır. Ancak alan kısıtından dolayı bulgular yerine yalnızca yorumlara değinilmiştir. Sonuçlar parametre ayarlama dönemlerinde üç yöntemde de oldukça benzerken doğrulama döneminde PSO biraz daha iyi sonuç vermiştir. Tahmin edilen parametreler ise birbirine yakındır. Teğetler yönteminde optimizasyon süreci boyunca model parametreleri için farklı başlangıç değerleri seçilerek algoritmanın lokal minimum noktalara takılması ihtimali azaltmaya çalışılmıştır. PSO'da parçacıkların arama uzayındaki hareketini farklı şartlara göre ayarlayan hız bileşeni bulunduğundan ve olayın rastgele karakteri de dikkate alındığından, PSO klasik yöntemlerde rastlanılan bu dezavantajları en aza indirgemektedir. Parametre tahminleri üç yöntemde de benzer olmakla birlikte, PSO'nun GA'dan ve Teğetler yönteminden daha hızlı sonuç vermesi ve oldukça basit bir işleyişe sahip olması PSO’yu parametre tahmini aşamasında daha cazip kılmaktadır.

Çalışmada PSO kalibrasyonu ile hazırlanan su bütçesi modeli az veriye ihtiyaç duyması ve kolaylıkla uygulanabilirliği bakımından oldukça pratiktir. Ancak yöntemlerin farklı klimatolojik özelliklere sahip havzalarda da uygulanması ve farklı modeller ile kıyaslanması yararlı olacaktır.

\section{Teşekkür}

Bu çalışma, Türkiye Bilimsel ve Teknolojik Araştırma Kurumu (TÜBİTAK) - Çevre, Atmosfer, Yer ve Deniz Bilimleri Araştırma Destek Grubu (ÇAYDAG) tarafından desteklenen 114Y716 numaralı proje kapsamında hazırlanmıştır. Çalışmayı inceleyen hakemlere önerilerinden dolayı ayrıca teşekkür ederiz.

\section{Kaynaklar}

Atkinson S.E., Woods R.A., Sivapalan M., (2002), Climate and landscape controls on water balance model complexity over changing timescales, Water Resource Research, 38 (12), 1-17.

Budyko M.I., (1958), The Heat Balance of the Earth's Surface, U.S. Department of Commerce, Weather Bureau, Washington, DC.

Chau K.W., (2006), Particle swarm optimization training algorithm for ANNs in stage prediction of Shing Mun River, Journal of Hydrology, 329 (3-4), 363-367.

Choudhury B.J., (1999), Evaluation of an empirical equation for annual evaporation using field observations and results from a biophysical model, Journal of Hydrology, 216, 99-110.

Chu H., Chang L., (2009), Applying Particle Swarm Optimization to Parameter Estimation of the Nonlinear Muskingum Model, Journal of Hydrologic Engineering, 14(9), 1024-1027.

Farmer D., Sivapalan M., Jothityangkoon C., (2003), Climate, soil, and vegetation controls upon the variability of the water balance in temperate and semiarid landscapes: downward approach to water balance analysis, Water Resource Research, 39(2), 1-21.

Fıstıkoğlu O., Harmancıoğlu N., (2001), Yukarı Gediz havzasında aylık su bütçesi modeli uygulaması, III. Ulusal Hidroloji Kongresi, İzmir.

F1stıkoğlu O., Okkan U., (2010), Tahtalı havzası için aylık su bütçesi modeli, VI. Ulusal Hidroloji Kongresi, Denizli, 546-554.

Fu B.P., (1981), On the calculation of the evaporation from land surface, Scientia Atmospherica Sinica, 5, 23-31.

Gill M.K., Kaheil Y.H., Khalil A., McKee M., Bastidas L., (2006), Multiobjective particle swarm optimization for parameter estimation in hydrology, Water Resource Research, 42 (7), 1-14. 
Goswami M., O'Connor K.M., (2007), Comparative assessment of six automatic optimization techniques for calibration of a conceptual rainfall-runoff model, Hydrological Science Journal, 52(3), 432-449.

Kennedy J., Eberhart R.C., (1995), Particle Swarm Optimization, In Proceedings of IEEE International Conference on Neural Networks, 4, 1942-1948, Perth, Australia, IEEE Service Center, Piscataway, NJ.

Kuok K.K., Harun S., Chiu P.C., (2011), Comparison of Particle Swarm Optimization and Shuffle Complex Evolution for AutoCalibration of Hourly Tank Model's Parameters, Int. J. Advance. Soft Comput. Appl., 3(3), 1-17.

Makhlouf Z., Michel C., (1994), A two-parameter monthly water balance model for French watersheds, Journal of Hydrology, 162, 299-318.

Milly P.C.D., (1994), Climate, soil water storage, and the average annual water balance, Water Resource Research, 30, $2143-2156$.

Moriassi D.N., Arnold J.G., Van Liew M.W., Bingner R.L., Harmel R.D., Veith T.L., (2007), Model evaluation guidelines for systematic quantification of accuracy in watershed simulations, Transaction of the ASABE, 50(3), 885-900.

Okkan U., Inan G., (2015), Statistical downscaling of monthly reservoir inflows for Kemer watershed in Turkey: Use of machine learning methods, multiple GCMs and emission scenarios, International Journal of Climatology, 35, 3274-3295.

Reddy M.J., Kumar D.N., (2007), Multi-objective particle swarm optimization for generating optimal trade-offs in reservoir operation, Hydrological Processes, 21, 2897-2909.

Xu C.Y., Singh V.P., (1998), A Review on Monthly Water Balance Models for Water Resources Investigations, Water Resources Management, 12, 20-50.

Zhang L., Potter N., Hickel K., Zhang Y.Q., Shao Q.X., (2008), Water balance modeling over variable time scales based on the Budyko framework - model development and testing, Journal of Hydrology, 360 (1-4), 117-131. 